\title{
Catalytic Wacker-type Oxidations using Visible Light Photoredox Catalysis
}

\author{
Yee Ann Ho, ${ }^{[a]}$ Eva Paffenholz, ${ }^{[a]}$ Hyun Jin Kim,,${ }^{[a, b]}$ Benjamin Orgis,,${ }^{[a]}$ and Magnus Rueping, ${ }^{[a, c]}$ and \\ David C. Fabry ${ }^{*}[\mathrm{a}, \mathrm{d}]$
}

\begin{abstract}
A combined palladium / photoredox catalytic system for the efficient oxidation of terminal olefins to the corresponding methyl ketones is presented. The interplay of air, water, and light leads to a protocol in which the stoichiometric oxidants required for oxidative palladium catalysis are substituted with catalytic, single-electron transfer processes. Detailed mechanistic investigations revealed the role of the key components, in situ generated species, and catalysts. A broad range of substrates was examined in homogeneous as well as heterogeneous photoredox protocols, delivering the desired products in good yields.
\end{abstract}

Palladium catalyzed reactions can be considered as cornerstone of transition metal catalysis. Due to the diversity of possible catalytic pathways, various reactions, including oxidations can be facilitated for the synthesis of bulk and fine chemicals. ${ }^{[1]}$ For this reason palladium catalysis, honored by the 2010 Nobel prize, ${ }^{[2]}$ has emerged as one of the most investigated fields in organic chemistry. Beside its utility in the fine chemical industry, for the synthesis of pharmaceuticals and agrochemicals, palladium catalysis has also found extensive application in the synthesis of bulk chemicals. ${ }^{[3]}$ Among the well-established protocols, the Wacker oxidation describes a basic reaction for the synthesis of methyl ketones. ${ }^{[4]}$ Starting from terminal olefins, a regioselective oxidation with water as oxygen source can be conducted. As a sacrificial oxidant, that is generally required for oxidative palladium catalysis, stoichiometric copper(II) salts found application for the oxidation of the in situ generated $\mathrm{Pd}(0)$ species. ${ }^{[5]}$ Next to this classical version, alternatives have been developed by Sigman $^{[6 a]}$ and Kaneda, ${ }^{[6 b]}$ however, creating significant concerns regarding the safety issues, due to strong positive oxygen atmospheres in organic solvents at elevated temperatures. ${ }^{[6]}$ Moreover, organic peroxides as oxygen source have been used, though still accompanied by the above mentioned metal salt additives and safety issues. ${ }^{[7]}$

[a] Dr. Y. A. Ho, M. Sc. E. Paffenholz, Dr. H. J. Kim, M. Sc. B. Orgis, Prof. Dr. M. Rueping, Dr. D. C. Fabry Institute of Organic Chemistry, RWTH Aachen University, Landoltweg 1, D-52074 Aachen, Germany E-mail: david.fabry@rwth-aachen.de

[b] Dr. H. J. Kim

Korea Research Institute of Chemical Technology, 141 Gajeongro, Yuseong, Daejeon 34114, Republic of Korea

[c] Prof. Dr. M. Rueping

KAUST Catalysis Center (KCC), Thuwal 23955-6900, Saudi Arabia

[d] Dr. D. C. Fabry

Tokyo Institute of Technology, Department of Chemistry, Ookayama 2-12-1-NE-1, Meguro-ku, Tokyo 152-8550, Japan

Supporting information for this article is given via a link at the end of the document
Photoredox catalysis has recently been proven as useful and efficient tool in organic synthesis. Single-electron transfer (SET) reactions could be carried out with the aid of catalytic amounts of a photoredox catalyst, using visible light as abundant and green energy source. ${ }^{[8]}$ This concept could be extended over the years to more sophisticated applications. ${ }^{[9]}$ Especially the uprising area of dual or combined catalysis has become a main area of research. $\left.{ }^{[9 a}, 10\right]$ Therein, the photoredox catalyst is mainly used for both, activation of the substrates as well as oxidation or reduction of the metal intermediates. For the previously described Wacker oxidation that requires stoichiometric amounts of an oxidant, photoredox catalysis represents a suitable option to address this problem. In principle, single electron transfer catalysts, such as the classical photoredox catalysts $\left[\mathrm{Ru}(\mathrm{bpy})_{3}\right]\left(\mathrm{PF}_{6}\right)_{2}$ and $\left[\operatorname{lr}(\mathrm{ppy})_{2}(\mathrm{bpy})\right] \mathrm{PF}_{6}$, should be able to oxidize the intermediate $\mathrm{Pd}(0)$ species back to $\mathrm{Pd}(\mathrm{II})$.

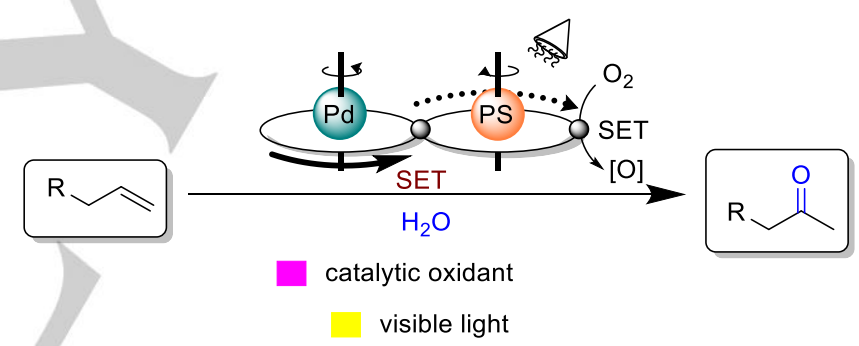

Scheme 1. Concept of the combined photoredox / palladium catalyzed oxidation of terminal olefins to the corresponding ketones.

Based on previous work from our group, ${ }^{[11]}$ we began our investigation for the catalytic Wacker oxidation using photoredox catalysis and visible light. We started with the oxidation of allylbenzene 1 as model substrate in the presence of water and examined the role of the palladium(II) catalyst first. As already described in the literature, ${ }^{[4-5]}$ we found that only ligand-poor palladium precursors work in this reaction. As a matter of fact, especially only weak-coordinating ligands could deliver the corresponding product $\mathbf{2}$ in higher yields due to the comparably weak coordination affinity of the allyl moiety in the substrate (for detailed optimization studies, see SI). Palladium(II) chloride worked the best with a yield of $35 \%$ for the corresponding ketone 2, whereas palladium(II) acetate and palladium(II)-allyl chloride dimer showed only poor reactivity (Table 1, entries 1-3). Next we examined the role of the solvent, and DMF proved to be the best (Table 1, entries 3-6). When water, as assumed oxygen source, was omitted, the desired ketone 2 was isolated in $3 \%$ yield only (Table 1, entry 7 ), emphasizing that the origin of the keto-oxygen lies in the water and not in the air-oxygen. Water as sole solvent showed also poor reactivity since, on one hand, DMF, as catalyst- 
stabilizing solvent, was not present, and on the other hand, the components were only partially or not at all soluble (Table 1, entry $8)$. Decreasing the amount of water led to an improved yield of $62 \%$ (Table 1 , entry 12 vs 3 ).

Table 1. Optimization of the Wacker-type oxidation reaction. [a]

$$
\underset{1}{\frac{\mathrm{Pd}(\mathrm{II}) \text { catalyst }(10 \mathrm{~mol} \%)}{\left[\mathrm{Ir}(\mathrm{ppy})_{2}(\mathrm{bpy})\right] \mathrm{PF}_{6}(3 \mathrm{~mol} \%)}} \frac{\mathrm{DMF} / \mathrm{H}_{2} \mathrm{O}, 120^{\circ} \mathrm{C} \text {, air, white light }}{\longrightarrow}
$$

\begin{tabular}{ccccc}
\hline entry & $\mathrm{Pd}(\mathrm{II})$ & solvent & $\begin{array}{c}\mathrm{H}_{2} \mathrm{O} \\
\text { (equiv.) }\end{array}$ & $\begin{array}{c}\text { Yield }^{[b]} \\
(\%)\end{array}$ \\
\hline 1 & $\mathrm{Pd}(\mathrm{OAc})_{2}$ & $\mathrm{DMF}$ & 200 & 12 \\
2 & {$\left[\mathrm{Pd}(\mathrm{allyl}) \mathrm{Cl}_{2}\right]_{2}$} & $\mathrm{DMF}$ & 200 & - \\
3 & $\mathrm{PdCl}_{2}$ & $\mathrm{DMF}$ & 200 & 35 \\
4 & $\mathrm{PdCl}_{2}$ & $\mathrm{DMSO}$ & 200 & 17 \\
5 & $\mathrm{PdCl}_{2}$ & $\mathrm{MeCN}$ & 200 & 21 \\
6 & $\mathrm{PdCl}_{2}$ & $\mathrm{MeOH}$ & 200 & 7 \\
7 & $\mathrm{PdCl}_{2}$ & $\mathrm{DMF}$ & - & 3 \\
8 & $\mathrm{PdCl}_{2}$ & $\mathrm{H} 2 \mathrm{O}$ & - & 18 \\
9 & - & $\mathrm{DMF}$ & 200 & - \\
10 & $\mathrm{PdCl}_{2}$ & $\mathrm{DMF}$ & 200 & $12^{c}$ \\
11 & $\mathrm{PdCl}_{2}$ & $\mathrm{DMF}$ & 200 & $15^{d}$ \\
12 & $\mathrm{PdCl}_{2}$ & $\mathrm{DMF}$ & 150 & $62^{e}$ \\
13 & $\mathrm{Pd}\left(\mathrm{MeCN}_{2} \mathrm{Cl}_{2}\right.$ & $\mathrm{DMF}$ & 150 & $65^{e}$ \\
14 & $\mathrm{Pd}\left(\mathrm{MeCN}_{2} \mathrm{Cl}_{2}\right.$ & $\mathrm{DMF}$ & 150 & $61^{e, f}$ \\
15 & $\mathrm{Pd}\left(\mathrm{MeCN}_{2} \mathrm{Cl}_{2}\right.$ & $\mathrm{DMF}$ & 150 & $91^{e, g}$ \\
$16^{h}$ & $\mathrm{Pd}\left(\mathrm{MeCN}_{2} \mathrm{Cl}_{2}\right.$ & $\mathrm{DMF}$ & 150 & $65^{e}$ \\
\hline
\end{tabular}

[a] Reaction conditions: 1 (0.1 mmol), Pd(II) (10 mol\%), [Ir(ppy) 2 (bpy)]PF 6 (3 $\mathrm{mol} \%)$ in DMF/H2O $(6: 1)$ at $120^{\circ} \mathrm{C}$ using an $11 \mathrm{~W}$ CFL bulb, $24 \mathrm{~h}$. [b] Yields determined by GC. [c] Without photoredox catalyst. [d] Without light. [e] Yields after chromatographic purification. [f] Reaction under $1 \mathrm{~atm} . \mathrm{O}_{2}$. [g] 20 mol\% [Ir] were used. [h] Reaction on $0.2 \mathrm{mmol}$ scale with $15 \mathrm{~mol} \% \mathrm{Pd}(\mathrm{II})$.

Control reactions were next performed. When the palladium catalyst was omitted, no product could be isolated, hence proving that the desired oxidation reaction is not a sole photoredox triggered process (Table 1, entry 9). In the absence of the photoredox catalyst, only stoichiometric conversion of allylbenzene 1 (12\% yield of ketone 2 ), with respect to the amount of palladium catalyst ( $10 \mathrm{~mol} \%$ ), could be observed (Table 1 , entry 10). This underlines the mechanistic proposal in which the in situ generated $\operatorname{Pd}(0)$ species cannot be oxidized without an additional oxidant. In the absence of light, ketone 2 was obtained in 15\% yield (Table 1, entry 11), stressing that the photoredox catalyst itself cannot function as oxidant in its ground state. Efficient oxidation of the $\operatorname{Pd}(0)$ occurs only with the photoredox catalyst in the excited state. Since small amounts of palladium black were observed after the reaction, $\mathrm{Pd}(\mathrm{MeCN})_{2} \mathrm{Cl}_{2}$ was additionally screened as $\mathrm{Pd}(\mathrm{II})$ precursor to introduce stabilizing, weakcoordinating ligands to the metal center. We hoped that the resulting $\mathrm{Pd}(0)$ complex would stay in solution for longer time and would not precipitate as palladium black thereby. Indeed, under these reaction conditions, less palladium black was observed and a higher yield of $65 \%$ for ketone 2 was obtained. Although full conversion of the starting material was detected using allylbenzene 1 as substrate, $\beta$-methylstyrene as side product (arising from $\mathrm{Pd}(\mathrm{II})$-catalyzed double bond isomerization) was observed, explaining the moderate yield of ketone 2 (for detailed optimization of ligands, water content, additive, photoredox catalyst, see $\mathrm{SI}$ ).

With $10 \mathrm{~mol} \%$ of $\mathrm{Pd}(\mathrm{II})$ catalyst and $3 \mathrm{~mol} \%$ of $\left[\operatorname{Ir}(\mathrm{ppy})_{2}(\mathrm{bpy})\right] \mathrm{PF}_{6}$ as optimized reaction conditions, the detailed role of oxygen and photoredox catalyst was investigated (see SI). Under the standard reaction conditions, the formation of a plateau after five hours reaction time could be observed, accompanied by a lower conversion of the substrate. Since from this moment onwards no palladium black was formed, which could have explained the lower yields, we assumed that the reoxidation process of $\operatorname{Pd}(0)$ was affected by the photoredox catalysis. Therefore, we conducted the same reaction under oxygen atmosphere assuming that faster regeneration of the photoredox catalyst would occur and the overall reaction performance would improve thereby, which however was not observed. We concluded that for this part of the reaction profile the palladium catalysis was the rate determining step and therefore the photoredox process is faster than the palladium catalysis. When the amount of photoredox catalyst was increased to $20 \mathrm{~mol} \%$, the same conversions were observed for the initial phase of the reaction, thereby confirming the previous assumption; however, the described plateau formation did not occur anymore. The reaction proceeded with the afore indicated reaction rate and delivered the desired product 2 in $91 \%$ yield.

With the obtained information, the following reaction mechanism can be proposed (Scheme 2):

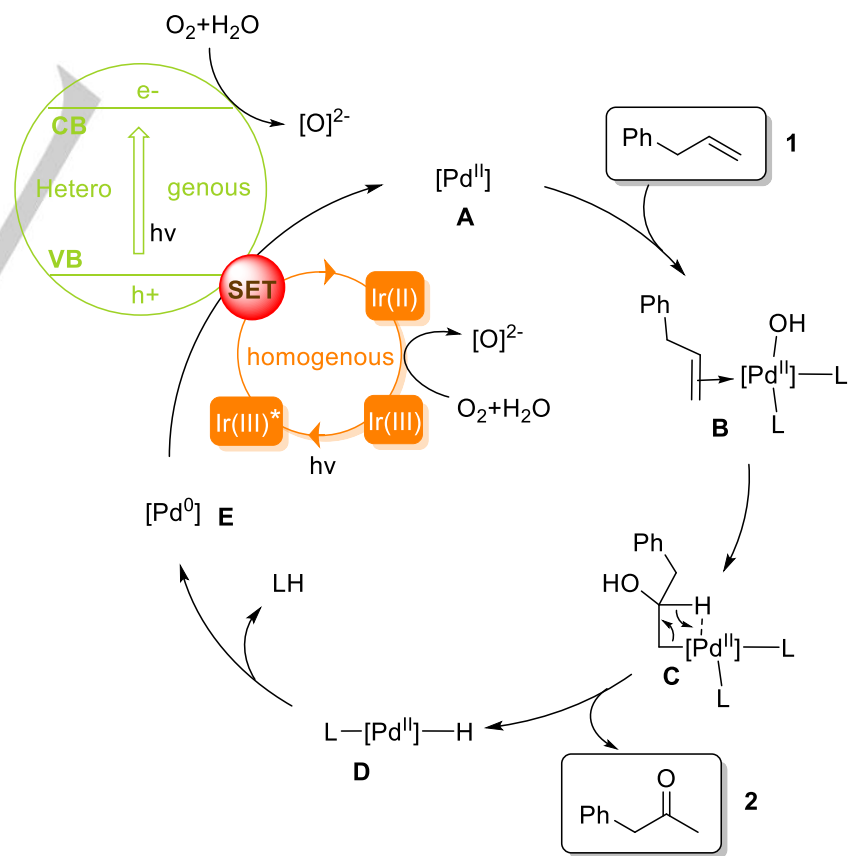

Scheme 2. Concept of the combined photoredox / palladium catalyzed oxidation of terminal olefins to the corresponding ketones.

Starting from palladium(II) precursor A, coordination of the allyl moiety in substrate $\mathbf{1}$ occurs, at the same time binding water as hydroxyl group at the palladium center (complex B). Palladium(II) 
itself, without water, can also coordinate to the allyl group forming $\beta$-methylstyrene as side product as described in the literature. The resulting complex $\mathbf{C}$ undergoes $\beta$-hydride elimination to give the desired product 2 and $\mathrm{Pd}(\mathrm{II})$-hydride $\mathbf{D}$. Ligand-H abstraction then results in $\mathrm{Pd}(0)$ as intermediate which cannot react further in the absence of an oxidant. The visible light excited $\operatorname{Ir}(\mathrm{III})^{*}$ photoredox complex is now capable of oxidizing the resulting $\operatorname{Pd}(0)$ back to its active $\mathrm{Pd}(\mathrm{II})$ species, being thereby reduced to $\mathrm{Ir}(\mathrm{II})$. Oxygen as sacrificial species undergoes reduction to superoxide anions at the same time regenerating the photoredox catalyst, whereas the superoxide anions immediately form hydrogen peroxide due to their reaction with water. ${ }^{[12]}$ Hydrogen peroxide itself can also work as oxidant, liberating again water for the addition reaction.Since only small quantities of peroxide are formed and they react immediately, ${ }^{[13]}$ this methodology seems to be advantageous compared to commonly used peroxide-based olefin oxidation reactions which usually require large excess of peroxides.

With the necessary tools for the reaction in hand, we began to examine the substrate scope of the combined $\mathrm{Pd} /$ photoredoxcatalyzed reaction (Scheme 3). Upon extending the allyl chain by one methylene segment, we were pleased to see that the undesired side reaction was suppressed and the desired ketone 3 was obtained in a good yield of $81 \%$.

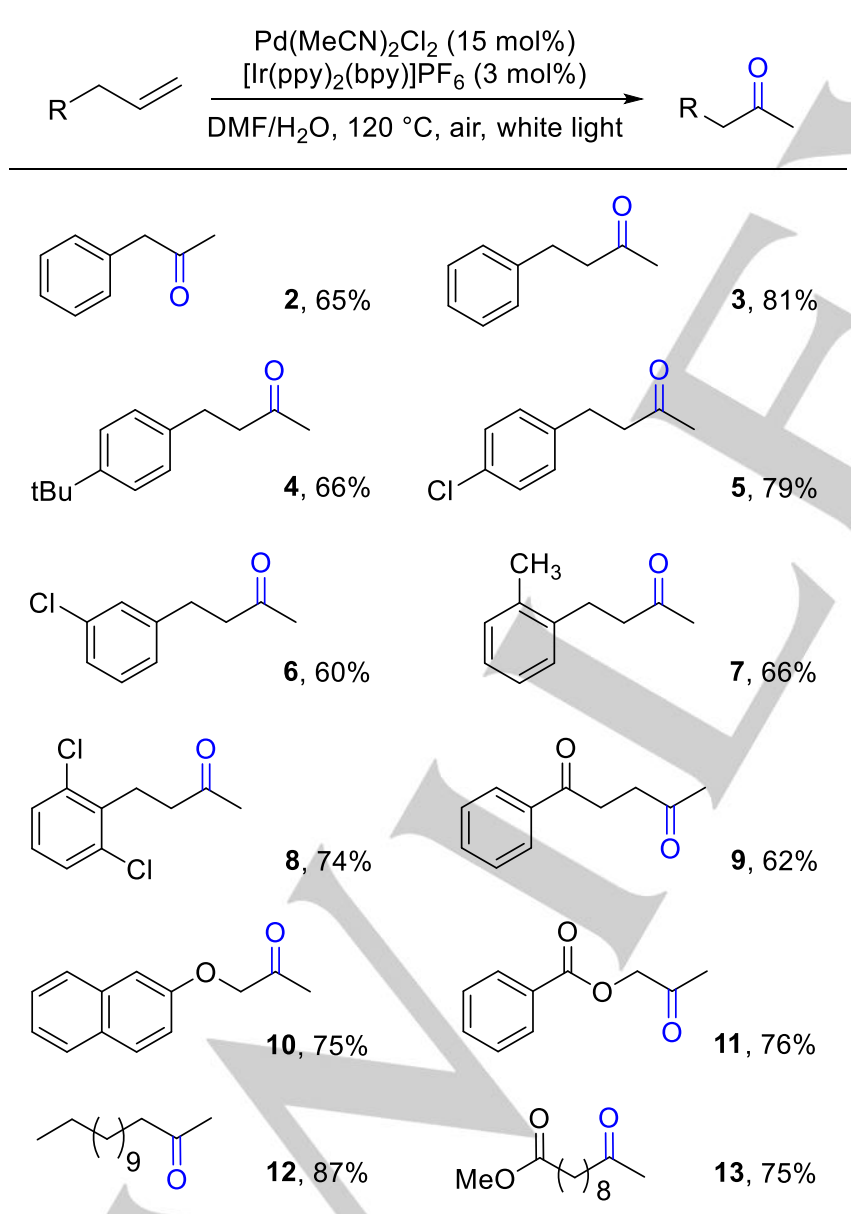

Scheme 3. Reaction scope of the photoredox / Pd catalyzed Wacker-type oxidation reaction; [a] Reaction conditions: $0.2 \mathrm{mmol}$ substrate in $\mathrm{DMF} / \mathrm{H}_{2} \mathrm{O}(6: 1)$ at $120^{\circ} \mathrm{C}$ using $11 \mathrm{~W}$ CFL bulb, $36 \mathrm{~h}$, yields after chromatographic purification.
Electron-rich arenes led to slightly lower yields, whereas electronpoor substituents showed no negative impact, delivering the corresponding products 4-8 in moderate to good yields. Moreover, 1,4-diketone 9, ketoether $\mathbf{1 0}$, and ketoester 11 could be successfully synthesized. Lastly, it could be demonstrated that aliphatic olefins and unsaturated esters are tolerated substrates in this reaction, delivering the desired products 12 and 13 in good yields.

Based on these results, we questioned whether a heterogeneous photoredox catalyst can also be effective for such a SET reaction. Following the mechanism in Scheme 2, the oxidation of $\mathrm{Pd}(0)$ should also be possible making use of valence and conducting band electrons in a semiconductor. Therein, a semiconductor would be irradiated with visible light, by which an electron would be transferred from the valence band to the conducting band. This electron then would be analog capable of oxygen reduction to superoxide anions. The resulting electron hole in the valence band works as electron acceptor for the electrons being delivered from the $\operatorname{Pd}(0)$ to $\operatorname{Pd}(I I)$ oxidation.

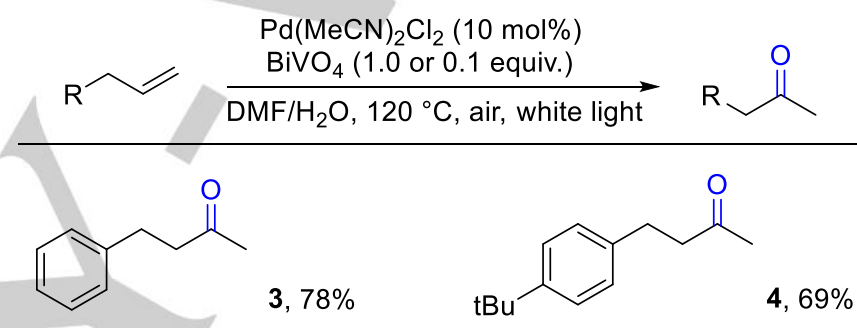<smiles>CC(=O)CCc1ccc(Cl)cc1</smiles>

$5,76 \%(70 \%)$<smiles>CC(=O)COC(=O)c1ccccc1</smiles>

$11,81 \%$<smiles>CCC(C)CC(C)=O</smiles>

$12,84 \%(73 \%)$<smiles>COC(=O)C(C)=O</smiles>

$13,79 \%$

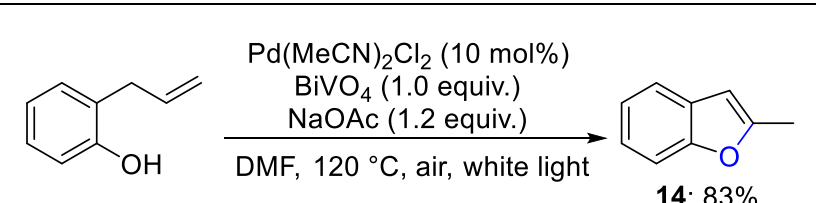

Scheme 4. Reaction scope of the heterogeneous-catalyzed Wacker-type oxidation reaction [a] Reaction conditions: $0.2 \mathrm{mmol}$ substrate in $\mathrm{DMF} / \mathrm{H}_{2} \mathrm{O}(6: 1)$ at $120^{\circ} \mathrm{C}$ using $11 \mathrm{~W}$ CFL bulb; yields after chromatographic purification; yields in parenthesis refer to reactions on a $0.4 \mathrm{mmol}$ scale and $10 \mathrm{~mol}^{\circ} \mathrm{BiVO}_{4}$.

A heterogeneous semiconductor which absorbs in the visible region of light and has recently been reported is bismuth vandate. ${ }^{[14]}$ The exchange of Ir-based photoredox catalyst with, at the beginning, one equivalent of a Bi-based semiconductor delivered ketone 3 in a good yield of $78 \%$ after only 18 hours. This showed that not only the change to a heterogeneous photoredox catalyst was achieved, but also a shortening of the reaction time could be realized. This catalyst $\left(\mathrm{BiVO}_{4}\right)$ was then tested for a variety of different substrates, giving similar yields as the previously described homogeneous photoredox catalyst (Scheme 
4). In order to increase the catalytic performance of the semiconductor which showed low reactivity at small scale reactions due to its low molecular weight and high density powder, $0.4 \mathrm{mmol}$ scale reactions using $10 \mathrm{~mol} \%$ of $\mathrm{BiVO}_{4}$ were tested, giving the desired products $\mathbf{5}$ and $\mathbf{1 2}$ in good yields and thereby proving its applicability as catalytic oxidant. Moreover, an intramolecular ring-closing oxidation reaction could also be performed, leading to the important methylbenzofuran structure $(14,83 \%)$.

In summary, this combined palladium-photoredox methodology demonstrates a new approach to a more sustainable reaction type for co-oxidant depending reactions using homogeneous or heterogeneous photoredox catalysis. A diverse range of substrates could be successfully applied in the reaction, making it a generously applicable methodology. Although similar methodologies are known, operating without additional oxidant, those reports pose enormous safety risks due to use of oxygen atmosphere in organic solvents at elevated temperatures. Photoredox catalysis can provide a safe alternative, making use of oxygen activation from ambient air.
Bottecchia, N. J. W. Straathof, V. Hessel, T. Noe, 2016; d) T. Chatterjee, N. Iqbal, Y. You, E. J. Cho, 2016; e) J.-r. Chen, X.-q. Hu, L.-q. Lu, W.-j. Xiao, 2016; f) N. Corrigan, S. Shanmugam, C. Boyer, 2016, 6165-6212; g) J. J. Douglas, M. J. Sevrin, C. R. J. Stephenson, 2016; h) M. D. Ka, J. A. Porco, C. R. J. Stephenson, 2016; i) T. Koike, M. Akita, 2016; j) R. Porta, M. Benaglia, A. Puglisi, 2016; k) A. P. Taylor, O. Fadeyi, 2016, 14; I) M. B. Plutschack, K. Gilmore, P. H. Seeberger, 2017; m) J. Xie, 2017, 5193-5203.

[10] for selected examples, see: a) D. C. Fabry, M. Rueping, Acc. Chem. Res. 2016, 49, 1969-1979; b) J. P. Goddard, C. Ollivier, L. Fensterbank, Acc. Chem. Res. 2016, 49, 1924-1936; c) M. N. Hopkinson, A. Tlahuext-Aca, F. Glorius, Acc. Chem. Res. 2016, 49, 2261-2272; d) X. Lang, J. Zhao, X. Chen, Chem. Soc. Rev. 2016, 45, 3026-3038; e) K. L. Skubi, T. R. Blum, T. P. Yoon, Chem. Rev. 2016, 116, 10035-10074; f) J. C. Tellis, C. B. Kelly, D. N. Primer, M. Jouffroy, N. R. Patel, G. A. Molander, Acc. Chem. Res. 2016, 49, 1429-1439; g) J. Twilton, C. Le, P. Zhang, M. H. Shaw, R. W. Evans, D. W. C. MacMillan, Nat. Rev. Chem. 2017, 1, 1.

[11] J. Zoller, D. C. Fabry, M. A. Ronge, M. Rueping, Angew. Chem. Int. Ed. 2014, 53, 13264-13268.

[12] Y. Che, M. Tsushima, F. Matsumoto, T. Okajima, K. Tokuda, T. Ohsaka, J. Phys. Chem. 1996, 100, 20134-20137.

[13] D. P. Kranz, A. G. Griesbeck, R. Alle, R. Perez-Ruiz, J. M. Neudorfl, K. Meerholz, H. G. Schmalz, Angew. Chem. Int. Ed. 2012, 51, 6000-6004

[14] Y. Park, K. J. Macdonald, K. S. Choi, Chem. Soc. Rev. 2013, 42, 23212337.

Keywords: Oxidation $•$ Ketone $\cdot$ Palladium $•$ Copper-free • Superoxide

\section{REFERENCES}

[1] for selected examples, see: a) T. W. Lyons, M. S. Sanford, Chem. Rev. 2010, 110, 1147-1169; b) T. Vlaar, E. Ruijter, B. U. Maes, R. V. Orru, Angew. Chem. Int. Ed. 2013, 52, 7084-7097; c) T. Gensch, M. J. James, T. Dalton, F. Glorius, Angew. Chem. Int. Ed. 2018, 57, 2296-2306; d) D. Roy, Y. Uozumi, Adv Synth Catal 2018, 360, 602-625.

[2] a) E. Negishi, Angew. Chem. Int. Ed. 2011, 50, 6738-6764; b) A. Suzuki, Angew. Chem. Int. Ed. 2011, 50, 6722-6737.

[3] S. Bhaduri, D. Mukesh, Homogeneous Catalysis, John Wiley \& Sons, 2014.

[4] a) J. A. Keith, P. M. Henry, Angew. Chem. Int. Ed. 2009, 48, 9038-9049; b) S. E. Mann, L. Benhamou, T. D. Sheppard, Synthesis-Stuttgart 2015 47, 3079-3117; c) D. Wang, A. B. Weinstein, P. B. White, S. S. Stahl, Chem. Rev. 2018, 118, 2636-2679.

[5] a) F. C. Phillips, Am. Chem. Soc. 1894, 16, 255-277; b) J. Smidt, W. Hafner, R. Jira, J. Sedlmeier, R. Sieber, R. Ruettiner, H. Kojer, Angew. Chem. 1959, 71, 176-182; c) J. Smidt, W. Hafner, R. Jira, J. Sedlmeier, A Sabel, Angew. Chem. Int. Ed. 1962, 1, 80-88.

[6] a) C. N. Cornell, M. S. Sigman, Org. Lett. 2006, 8, 4117-4120; b) T. Mitsudome, T. Umetani, N. Nosaka, K. Mori, T. Mizugaki, K. Ebitani, K. Kaneda, Angew. Chem. Int. Ed. 2006, 45, 481-485.

[7] a) B. W. Michel, A. M. Camelio, C. N. Cornell, M. S. Sigman, J. Am. Chem. Soc. 2009, 131, 6076-6067; b) R. A. Fernandes, D. A. Chaudhari, J. Org. Chem. 2014, 79, 5787-5793.

[8] for selected examples, see: a) F. Teply, Collect. Czech. Chem. Commun. 2011, 76, 859-917; b) N. Hoffmann, Austral. J. Chem. 2015, 68; c) D. Ravelli, S. Protti, M. Fagnoni, Chem. Rev. 2016, 116, 9850-9913; d) M. H. Shaw, J. Twilton, D. W. C. Macmillan, J. Org. Chem. 2016, 81, 68986926; e) D. Staveness, I. Bosque, C. R. Stephenson, Acc. Chem. Res. 2016, 49, 2295-2306; f) J. Xie, H. Jin, A. S. K. Hashmi, Chem. Soc. Rev. 2017, 46, 5193-5203.

[9] for selected examples, see: a) V. Balzani, A. Credi, M. Venturi, Photochemical Conversion of Solar Energy, 2008; b) R. Brimioulle, D. Lenhart, M. M. Maturi, T. Bach, 2015, 3872-3890; c) D. Cambie, C. 